\title{
Students Have a Right to Know: Transparency in the Teaching of Writing
}

Samantha Parkes

When I arrived in Managua, Nicaragua as an English Language Fellow in August 2011, I was assigned to work with teachers at the national university in Managua. At our first meeting, the chair of the English department at the national university asked me to observe the integrated English courses and write a report on my thoughts and make recommendations to help them improve the quality of instruction in the department. As I conducted my observations I noticed that the teachers would usually do a couple of speaking activities, a reading activity, and a listening activity (if they brought the 80s style boombox with them from the department). Then, at the end of class, as students were packing their bags and heading out the door, they would say something like this: "Ok everyone, today we talked about colors. Go home and write about colors.”

I found this assignment problematic for many reasons.

- Students did not know how much to write.

- Students did not know the format or genre.

o Write a list of colors?

o Write a paragraph about colors?

o What kind of paragraph? Descriptive? Compare and contrast?

- The teacher had not given the students an example so they might be likely to go home and think, “I don’t know what to do" and could tempted to plagiarize or not complete the assignment.

- Students did not have the prompt in their notebooks or photocopied from the teacher to guide them as they composed.

- $\quad$ Students did not know if/how they would be evaluated.

This experience helped me realize that there are a few simple concepts and principles in teaching writing that I took for granted, but when shared and practiced, could help teachers feel more confident when teaching writing and help students feel informed, prepared, and able to succeed.

With this in mind, I set out to give a series of teacher training workshops for university and high school English teachers with the goal of giving them some tools to become more effective writing instructors. During my 5-hour intensive workshop, I talked about how to sequence writing assignments throughout the semester, how to design a clear writing prompt and rubric, how to give effective feedback on content and how to comment on grammar by using symbols to draw the students' attention to the error, but then letting them correct it themselves. I gave this workshop in ten different cities all across Nicaragua, providing the teachers with sample prompts, rubrics, sample papers to critique and discuss with peers and a little instruction manual with all of the information from my presentation, so that they could read at home and share with other colleagues.

At the end of each workshop, I asked the teachers to fill out my own evaluation which asked them what they felt was the most important thing they learned during our time together. One of the most surprising recurring themes in my feedback were comments like, "I never thought about what my students have a right to know before."

This comment surprised me because out of the myriad of information and examples we had just talked about for a substantial amount of time—a mini writing pedagogy course of sorts, being transparent and "students' rights" were not what I perceived to be major themes. And yet, one of the major takeaways for some teachers was that "students have a right to know what you expect of them, what a successful assignment looks like, and how they will be evaluated."

Comments like these surprised me because they reflect what I, as an ESL teacher and a citizen in a developed country, take for granted. I was taught that in order for students to succeed, they need to be prepared. In order for them to be 
prepared they need to understand what I am asking them to do. It made sense to give my students assignments on paper or post prompts on Blackboard so they could refer to them as they begin writing, or if they had any questions throughout the writing process. It seems natural to show students a model of the assignment or to read and analyze one in class together. It makes sense to tell students what our criteria for success are and show them the rubric before they turn in the assignment so they do not forget a major component of the assignment and can judge for themselves if they have fulfilled the criteria for success.

Aside from using terms like "content validity" we take for granted that students should not be tested on material they have not yet been exposed to in our classes and that they should be aware of how they are going to be graded. From my perspective, as someone who often teaches multiple writing courses a semester, the clearer I am with my prompt and the better I make students understand my criteria and evaluation schema, the better my students will do on any writing assignment. I will receive higher quality drafts, and thus, my life will be easier as I comment on the drafts. Not until I talked with many Nicaraguan teachers did I perceive this not only as good pedagogical practice, but in some circles it is also perceived as what I would call a transparency issue or what my Nicaraguan colleagues might refer to as "students" rights.” If it were possible to do follow-up interviews with these teachers, I would be interested in knowing how this concept affected other parts of their lives in Nicaragua. It made me wonder what else they might begin thinking they had a right to know. 